\title{
A (RE)SIGNIFICAÇÃO DE POSTURAS FRENTE À EDUCAÇÃO A DISTÂNCIA*
}

\author{
Ana Maria Cardoso* \\ Moisés Lucas dos Santos* \\ Nivaldo Carleto* \\ Salete Genovez* \\ Simone Cecília Pelegrini da Silva*
}

RESUMO: As novas Tecnologias de Informação e Comunicação promovem inúmeras mudanças no comportamento social e cultural em nossos dias. O que se sabe é que o impacto deste fenômeno repercute em inúmeros setores sociais, mas é na forma de comunicação e na educação que estes fatores ganham força. Aliás, o modo como o sujeito do século XXI faz uso e como se expressa através destes instrumentos talvez defina uma inegável quebra de paradigmas. Se as gerações anteriores estavam acostumadas a assistir a programas televisivos quase sempre relacionados à aplicabilidade e venda de um produto ou à determinação de comportamentos, agora, a interação através da internet e redes sociais redefine posturas. Este artigo reflete acerca dos condicionamentos impostos ao telespectador para, num segundo momento, discutir de que maneira as novas ferramentas de TICs podem contribuir para uma dinâmica aprendizagem em rede. Nesta perspectiva, se fez um levantamento de artigos científicos, a fim de procurar compreender em que medida os estudantes têm se servido dos meios disponíveis para a interação em rede e no ambiente de aprendizagem online. O que se verifica, no entanto, é que os aprendizes ainda não conseguem se apoderar dos espaços de interação que estão a sua disposição, o que indica ser este um dos obstáculos para se vincular ao curso. O mau uso da linguagem e a falta de um sentimento de pertencimento, infelizmente, têm contribuído para que os estudantes ainda relutem ou se sintam perdidos no ambiente de educação a distância.

PALAVRAS-CHAVE: Educação a distância. Mídias. Literatura Brasileira.

As novas tecnologias de informação suscitam profundas mudanças socioculturais que a sociedade ainda não tem condições de compreender em sua totalidade. Sempre que se modificam aspectos sociais, surgem resistências, pois não ainda se tem clareza do seu impacto e, ao mesmo tempo, é difícil avaliar como estas

\footnotetext{
"Grupo de Pesquisa da Faculdade Anhanguera. Imeio: ana.mcardoso@aedu.com.

*Faculdade Anhanguera. Imeio: oficinadeliteratura@yahoo.com.br.

*Faculdade Anhanguera. Imeio: moises.lucas@aedu.com.

*Faculdade Anhanguera. Imeio: nivaldo.carleto@aedu.com.

* Faculdade Anhanguera. Imeio: maria.genovez@aedu.com.

*Faculdade Anhanguera. Imeio: simone.cpsilva@sp.senac.br.
} 
transformações se perpetuarão ao longo dos tempos. Os olhares apontam para as mudanças em torno do uso da linguagem e do ensino a partir do uso das TICs nos dias de hoje.

Através das redes sociais, nota-se que a comunicabilidade em rede deu oportunidade para que o conteúdo prepondere em detrimento da linguagem. As atuais práticas de comunicação fazem com que a oralidade prevaleça diante da escrita, apesar de as instituições de ensino demarcarem claras distinções entre língua falada e língua escrita. Frente às práticas cotidianas, os textos produzidos em sala de aula trazem em si cada vez mais mesclas de oralidade, o que originou a definição comumente utilizada como o internetês. Os professores, por sua vez, veem a nova situação com perplexidade, mas se faz necessário refletir sobre estas mudanças na produção de textos dos estudantes. Isto porque os usuários em rede utilizam a linguagem intensamente e se comunicam numa velocidade nunca antes vista. Assim, a formalidade da língua padrão anunciada pelos arautos das academias de letras não é um limite para os usuários em rede que se comunicam, trocam, se divertem e se relacionam em meio à avalanche de situações comunicacionais que se define como a Sociedade da Informação.

As redes sociais como Facebook, Orkut, Msn, entre outras, promovem dia a dia formas de interação que encantam pela diversidade de informações em múltiplas linguagens: visual, sonora, interativa. Crianças e adolescentes, envolvidos com estes novos instrumentos, tendem a resistir à escola, pois os clássicos paradigmas de ensino não as desafiam mais. É possível dizer, inclusive, que as instituições de ensino são vistas com certa desconfiança, principalmente pelos estudantes universitários, pois percebem que os profissionais inseridos no mercado de trabalho se valem das TICs. Nestas condições, o modelo de escola que repassa conteúdos e os avalia através de exercícios distantes do cotidiano cai em descaso frente ao olhar dos jovens do século XXI. Eles desejam incorporar os meios audiovisuais em suas práticas estudantis e a gama de riquezas que as tecnologias da informação apresentam. 
Assim, o interesse das gerações nascidas a partir dos anos 80 vai além da mera assimilação de conteúdos, pois querem dialogar e, de preferência, recriar, experimentar outras linguagens diante do que aprendem. O conceito de "nativos digitais" (BELLONI, 1999) define estes jovens com muita propriedade, pois, frente à geração dos "imigrantes digitais", eles possuem habilidades e competências para o uso das novas ferramentas e ainda interagem no ambiente em rede com extrema familiaridade e eficácia. Daí o compartilhamento de informações é realmente uma marca dos novos tempos da web, em que os jovens procuram e desejam criar juntos, muito próximos do que Pierre Lévy (1999) definiu como inteligência coletiva. Neste tráfego, também se vê um interesse muito expressivo em agregar pessoas em torno de causas sociais, como por exemplo, na defesa do meio ambiente ou no empoderamento de grupos excluídos socialmente como mulheres, negros, gays. No entanto, na rede de informações existem muitos desafios a serem desvendados, pois, se por um lado, ela exerce grande fascínio, por outro, seus caminhos podem ser nebulosos em igual medida.

Este artigo pretende tratar da mudança de paradigmas que se opera a partir da interação com as tecnologias de informação e comunicação, tanto na linguagem quanto na educação a distância. Para tanto, a narrativa curta de $O$ telespectador, de Frei Betto, se torna uma referência significativa com vistas a refletir acerca do modo de interação com a programação televisiva, principal meio de comunicação de massa, para, adiante, discutir as mudanças que surgem com a internet, especialmente no que se refere à educação e à linguagem. É nesta perspectiva que se definirá os rumos deste trabalho.

\section{O olhar televisivo}

A partir dos anos 70, as gerações cresceram em frente a um aparelho de TV deixando-se seduzir, desde o início, por um universo de imagens e narrativas que seguiu encantando adultos, crianças e adolescentes ao longo dos anos. O veículo alcançou grande popularidade, instalando-se triunfante na maior parte dos lares, inclusive nos locais mais distantes. O que se sabe é que a televisão exerceu uma 
influência importante na formação cultural dos brasileiros, como foi o rádio e o cinema para as gerações antecessoras.

A imposição do silêncio, através das rígidas leis da censura no período ditatorial, dominou o país por vinte anos e deixou marcas profundas em nossa formação social e cultural. ${ }^{1}$ Diante disso, a televisão se tornou o principal veículo a divulgar a ideologia dominante nos anos de chumbo que, em paralelo com a restrição da liberdade política, estimulou a formação de consumidores. Em outras palavras, o período ditatorial obteve nos meios de comunicação de massa um forte aliado na divulgação de suas ideias e, ao mesmo tempo, uma ferramenta para o estímulo do desenvolvimento econômico e abertura ao mercado internacional. Outro fator que somou esforços para estas mudanças foi o êxodo do meio rural, que ampliou a presença da televisão nas cidades, tornando-a o meio mais utilizado para o entretenimento. Há que se considerar ainda a inevitável violência das metrópoles, que por conta de um jornalismo cada vez mais sensacionalista, fez com que a população se fechasse em si mesma nos seus apartamentos e lares, isolados uns dos outros, e tendo a televisão como seu principal interlocutor.

É desafiador que gerações acostumadas a assistir a programas televisivos quase sempre relacionados à aplicabilidade e venda de um produto ou à disseminação de determinado comportamento, se vejam agora diante de novas formas de interação promovida, sobretudo, pela internet ao longo das últimas décadas. Frei Betto irá refletir como se incorpora este traço cultural no perfil do telespectador. Aliás, a coletânea acentua o destino dos indivíduos frente às forças sombrias impostas pela indústria cultural, análogas ao que será conceituado como Inferno, e questiona as consequentes mudanças culturais resultantes da recepção deste veículo. Viriato, protagonista de $O$ telespectador, habituado a uma vida de indiferença e devassidão, se vê diante do pós-morte e intui que seu

\footnotetext{
${ }^{1} \mathrm{O}$ período da ditadura no contexto brasileiro promoveu inúmeras mudanças na cultura e na sociedade; a produção cultural, sobretudo a literatura, modificou a sua expressão de linguagem em razão da imposição do silêncio e da violência do sistema político. Cf. CARDOSO, Ana Maria. In: _. Sonho e transgressão em Caio Fernando Abreu: o entrelugar de cartas e contos. Tese de Doutorado, UFRGS, 2007.
}

Texto Digital, Florianópolis, v. 8, n. 2, p. 3-18, jul./dez. 2012. ISSNe: 1807-9288 
comportamento pouco virtuoso não the permitiria galgar espaços elevados perante o Criador.

Viriato é conduzido pelo seu Anfitrião ao local em que pagará a sua pena. Depara-se, contudo, com uma sala clara e asséptica, que possuía apenas uma cadeira e um televisor e no mais completo isolamento. $O$ fato de o sujeito estar num ambiente excessivamente limpo, como num hospital, é simbólico, porque ali não Ihe é possível trazer as marcas que definem a sua identidade. O protagonista, neste caso, é desprovido de cultura, pois não trouxe consigo a bagagem de suas vivências e seus laços de afeto são praticamente inexistentes. Apreensivo, num primeiro momento, com a possibilidade de um total isolamento e solidão, minutos depois, ele vibra diante do que the é oferecido: uma rede infinita de canais disponíveis. Contudo, Ihe foi imposto determinadas condições. Ele deveria estar à frente da televisão durante 24 horas, sem interrupção, nem sequer para dormir ou se alimentar, sendo que Ihe era impossível desligá-la ou baixar o volume, ad eternum.

Assim que seu anfitrião se retira, ele tenta ir à porta, mas descobre que está preso à poltrona. Ele se coisificou tal como o móvel da sala. No entanto, ele não se abala com a situação, o que sugere que o papel que lhe fora imposto não era uma novidade. $O$ universo ficcional traça o perfil dos sujeitos metropolitanos que, isolados, preenchem suas angústias com os programas televisivos, pois as trocas subjetivas com os demais não despertam seu interesse; ele que, ao que parece, se condicionou ao papel de mero consumidor de imagens e ideias préestabelecidas. A indiferença ou embotamento dos sentidos define sua personalidade, o que faz com que, simbolicamente, ele se torne uma presa fácil para o consumo. Ele confunde sentimentos e desejos, pois tem os olhos vendados pela ilusão:

ele tinha ânsias de consumo e, no entanto, estava impedido de acesso ao mercado. E seu desejo desenrolava-se como um fio infinito. Seria menos doloroso se a sua auto-estima não estivesse sendo minada dia a dia. Não possuir aqueles produtos que conferiam valor a seus proprietários acarretava-lhe um sofrimento 
que the parecia sempre insuportável. Sentia-se faminto diante de um banquete, mas com a boca irremediavelmente costurada (BETTO, 2000, p. 114)

No entanto, após o período de três meses de encarceramento e total servidão ao que o aparelho Ihe impunha, Viriato percebe que a TV não era uma mera transmissora de atrativos, mas se tornava um "ente real" que pensava por ele, sonhava por ele, imaginava por ele, em suma, sentia-se completamente esvaziado em sua identidade. Inclusive o longo tempo exposto à mídia televisiva e à série de programas intercalados não Ihe permitia pensar acerca do que está sendo apreciado. Ele sente-se exaurido, pois a força da criatividade, das trocas, dos diálogos havia sido suprimida por meras cópias e reproduções acabadas. $\mathrm{O}$ tempo tornava-se um só, "já não havia passado, presente ou futuro", e o espaço subjetivo do telespectador tinha se esgotado em razão de um excesso de imagens, fragmentos de ideias e assuntos diversos. Viriato finalmente compreende a intensidade da penalidade que the fora imposta, pois se sentia "asfixiado por aquela profusão de signos que roubavam a palavra e sonegavam o silêncio, dilacerando-o interiormente".

As possibilidades de extravasar, as únicas possíveis enquanto consumidor, devido ao isolamento, não Ihe eram permitidas. Aqui a angústia acompanha o indivíduo que, apesar dos inúmeros estímulos midiáticos, não consegue sanar sua ambição desmedida. Subjulgado, ele se torna o objeto e a televisão ganha força e autonomia, pois esta é a influência nefasta que a programação televisiva pode the oferecer. A capacidade de nomear, que define os sujeitos, Ihe foi negada. Ele se tornara um sujeito raso, reificado. O embrutecimento dos sentimentos é estimulado, a fim de não sentir empatia pelos demais, sobretudo por aqueles que não estão dentro do que se considera o padrão de comportamento social:

[...] a programação saturava-o. Embora variada, obedecia aos mesmos modelos repetitivos. A beleza esguia das mulheres, a ridicularização dos homossexuais e dos gordos, a apologia ao adultério, a comicidade derivada da desgraça alheia, a prosperidade como fruto da sorte, a espetacularização da notícia, 
a nova embalagem de velhas piadas, velhas histórias e velhas imagens (BETTO, 2000, p.114).

É significativo que o sujeito isolado encontre uma forma de relaxar nos programas de entretenimento, mas, à medida que o tempo passa, o quadro se torne aprisionador. Se não há interação com o outro, as forças de autonomia e liberdade se esvaziam, pois a construção da identidade ocorre através dos diálogos, das trocas afetivas. É pela palavra que o pensamento pode ser expresso e ocorrem as trocas subjetivas, reconhecido em sua identidade cultural. Aqui o sombrio prevalece, sendo análogo ao Inferno, que o antropólogo Frei Betto pretende fazer o leitor questionar.

Outro aspecto relevante é o fato de que o veículo televisivo é uma forma de entretenimento sobretudo para os que se encontram isolados: os detentos, os aprisionados e os que, diante da falta de políticas públicas, como as crianças e idosos, não possuem atividades para além dos limites de seus lares. A formação cultural das mídias é um tema complexo, que exige um debate mais amplo e democrático, pois considerar os valores éticos e humanos é de fundamental interesse para se viver em sociedade.

\section{Interatividade e ensino a distância}

Superar a postura passiva do telespectador, a fim de se apropriar das novas ferramentas de TICs, como a internet, por exemplo, é realmente um salto para outra margem, um desafio para os sujeitos do século XXI. As pesquisas indicam um crescimento na modalidade em educação a distância e o formato metodológico e teórico de ensino presencial não pode ser apenas transferido para o ensino a distância, através das novas ferramentas. Exige-se um cuidado na preparação do material no sentido de atentar para as particularidades dos educandos e, assim, contextualizar os conhecimentos na região em que o aluno se situa. 
No ano de 2007, o governo decidiu estabelecer referenciais de qualidade para regulamentar os cursos de ensino a distância, a fim de minimizar os efeitos muitas vezes insatisfatórios desta modalidade de ensino, no momento de plena expansão do $\mathrm{EaD}$ no Brasil. Um dos aspectos enfatizados é de que um projeto de curso superior à distância precisa estar atento a um forte compromisso institucional com vistas a garantir a formação técnico-científica para o mundo do trabalho e, concomitantemente, considerar a dimensão política para a formação do cidadão. E mais: a educação superior - seja ela presencial ou a distância, nas inúmeras combinações possíveis entre presencial, presença virtual e à distância deve enfatizar o desenvolvimento humano, em uma perspectiva de compromisso com a construção de uma sociedade mais justa.

Outro aspecto importante no documento é o de que a educação deve superar a visão fragmentada do conhecimento, a fim de compor a estruturação curricular por meio da interdisciplinaridade e contextualização. Nesta perspectiva, a educação encontra um espaço desafiador e distinto dos meios de comunicação de massa, como o veículo televisivo, por exemplo. Se a televisão conta com um aparato voltado ao consumo e à padronização do pensamento, o arcabouço teórico e prático dos cursos de educação a distância tem um percurso que vai no sentido oposto, já que precisa levantar questionamentos, práticas e discursos inovadores para que ocorra um despertar da criatividade, da autonomia e da cidadania.

Neste sentido, a educação a distância deve propiciar um ambiente que promova a interação dos seus alunos entre si, através de fóruns e chats, destes com o professor e, essencialmente, na apreensão do conhecimento disponibilizado, de forma autônoma. Para tanto, é necessário destacar as diferenças entre interação e interatividade, que, muitas vezes se expressam de maneira difusa. Para Belloni (1999), o conceito sociológico de interação é a ação recíproca entre dois ou mais atores onde ocorre intersubjetividade, isto é, encontro entre dois sujeitos, que pode ser mediada por algum veículo técnico de comunicação (telefone ou carta). Já a interatividade é a potencialidade técnica que é disponibilizada por um 
determinado meio, como hipertextos em geral ou jogos eletrônicos. Há também o conceito de interatividade como a atividade humana que age sobre a máquina e de receber em troca uma "retroação".

Diante dos novos modelos de interatividade, é inevitável que o papel do professor também se modifique nesta quebra de paradigmas. O novo formato exige que 0 professor se torne um mediador do conhecimento e sua função se dissolva hierarquicamente em relação aos encontros clássicos que se davam em sala de aula. Antes, a aprendizagem ocorria, na maioria das vezes, através do seu arcabouço teórico e a partir daí ocorriam as trocas, os diálogos, enfim, o saber. Os docentes, mediadores em um novo espaço de conhecimento, não são os únicos referentes na aprendizagem; aliás, percebe-se que estas mudanças também se estenderam ao ensino presencial. Estudos demonstram que os professores, sempre atentos aos objetivos propostos pela disciplina, devem recorrer às múltiplas linguagens, a fim de diversificar a apreensão dos conteúdos, $e$ ir ao encontro do universo sociocultural dos seus educandos. Na atual quebra de paradigmas hierárquicos, o professor também é um aprendiz das linguagens visuais, sonoras, interacionais e cabe também a ele a autoaprendizagem inevitável ao novo contexto educacional.

Enfatiza-se, neste caso, a necessidade do letramento digital enquanto instrumento de inclusão social; vale dizer que incluir digitalmente não significa apenas 'alfabetizar' a pessoa em informática, mas também melhorar os quadros sociais a partir do manuseio dos computadores. Naturalmente que para que isto ocorra é necessário que o indivíduo seja letrado no seu idioma e que tenha certo domínio quanto aos códigos de leitura e escrita vigentes em sua sociedade para que, a partir dos mesmos, possa aproveitar as possibilidades que as TICs oferecem. Isto não é diferente no cotidiano dos professores, que necessitam não só dominar as tecnologias de informação e comunicação, como também reorganizar como irão disponibilizar os conteúdos e saberes para uma aprendizagem mais efetiva e próxima dos seus educandos. 
Assim, a quebra de paradigmas das práticas de TICs no educação são inúmeros e em muitas direções. $\mathrm{O}$ uso das redes sociais, como prática de interação social, tem ganhado um amplo número de adeptos, contudo a transposição da prática para o ambiente da aprendizagem, não conquista a mesma adesão e eficácia. Pesquisas demonstram que os alunos de educação a distância ainda não conseguem se apoderar de formas interativas que Ihes são disponibilizadas. Os ambientes virtuais de ensino, como fóruns, salas de bate-papo, emails ainda são utilizados de maneira insatisfatória pelo estudante, o que faz com ele não se sinta integrado ao curso do qual faz parte. Este fator é um dos determinantes para a evasão dos cursos na modalidade a distância (SERRA, 2005). Talvez por esta razão que a nova regulamentação (2007) tenha definido que os cursos precisam estimular e dar ênfase às trocas de saberes por meio de fóruns, salas de bate papo, chats, pois são estas formas de convivência que permitem que o aluno avance nas etapas de apreensão do conteúdo. Aliás, é por meio destes instrumentos que os alunos tendem a ter o sentimento de pertencimento ao curso do qual fazem parte.

Outro aspecto a considerar como obstáculo à interatividade, em especial ao eixo comunicativo (SERRA, 2005), diz respeito à dificuldade de expressão escrita que inevitavelmente acompanha os alunos, seja no ensino a distância, ou na educação presencial. As mensagens tendem a apresentar enunciados de duplo sentido, ou confusos, impedindo uma maior eficácia na resolução de problemas pelo professor/tutor na aprendizagem do ensino online. ${ }^{2}$ Há que se considerar ainda, que no turbilhão de informações encontradas na rede, os alunos têm dificuldades de pesquisar um determinado assunto, pois não distinguem o grau de relevância de um texto para outro, ou a confiabilidade dos endereços de pesquisa. Aqui se encontram competências indispensáveis ao saber e que se desenvolvem ao longo da prática de aprendizagem, seja a distância ou no ensino presencial.

Os cursos também precisam considerar o acesso aos meios tecnológicos: bibliotecas, laboratórios, videoteca, entre outros para seus educandos. Além

\footnotetext{
${ }^{2}$ A autora faz um estudo detalhado de como ocorre a interação comunicacional entre professores e alunos, a fim de verificar quais são os impedimentos de aprendizagem no ambiente online.
} 
disso, a educação, sobretudo na modalidade à distância, precisa contemplar cursos de caráter introdutório, a fim de sanar dúvidas quanto à alfabetização digital, a fim de que seus estudantes tenham condições de êxito, não só no curso do qual fazem parte, mas também no exercício de uma plena cidadania. E, por fim, é inegável que a o material a ser disponibilizado deve ser pensado e articulado por uma equipe multidisciplinar para que o ambiente de ensinoaprendizagem seja atrativo, com vistas a diminuir o crescente abismo que separa a escola da sociedade.

\section{Interatividade: possíveis caminhos}

Se as tecnologias de informação e comunicação ganham cada vez mais força no cotidiano dos indivíduos, quais são os possíveis caminhos para o estímulo do exercício de interação? Conforme levantamento de artigos científicos, a não interação provoca inevitavelmente uma ausência de laços de comunicação e, por extensão, uma falta de pertencimento ao ambiente de aprendizagem em rede. A mudança de comportamento, porém, vem sendo exercitada de forma espontânea através das redes sociais ou pelas buscas de informação através de matérias jornalísticas, músicas, blogs, entre outros. Nota-se que os usuários em rede apreciam, por exemplo, ao ler uma notícia em rede, expor o seu pensamento aos demais, em forma de comentários. Esta prática tem se tornado frequente, mas ela nem sempre contribui para um debate democrático; o que se nota é que, às vezes, as discordâncias não ajudam no crescimento através da troca de ideias, mas criam uma atmosfera de hostilidade entre alguns sujeitos, criando um ambiente constrangedor. Isto provavelmente está relacionado ao fato de que o indivíduo, nestas condições, se protege pelo anonimato e, em paralelo, confirma a dificuldade do exercício da cidadania que ocorre através do diálogo, a fim reformular inúmeros setores sociais que ainda carecem de mudança. Aliás, as dificuldades em criar um ambiente de trocas verdadeiramente efetivas em rede, através do debate, são as mesmas que se vê em sala de aula e em locais onde os cidadãos precisam chegar a um acordo em prol do bem comum, como em reuniões de condomínios, sindicatos, centros acadêmicos, entre outros. 
No entanto, o Orkut e o Facebook, enquanto redes sociais, têm demonstrado um envolvimento promissor no que diz respeito às comunidades associadas por um determinado assunto. Contudo, o fato de os participantes de comunidades estabelecerem trocas a partir de um interesse comum, em grande parte das vezes, demonstra um aprendizado que se estende para além do ambiente em rede. Há inúmeros debates e compartilhamento de textos, no momento em que se estuda um autor vinculado à literatura ou à música, por exemplo. Aliás, a colaboração, nestas condições, é surpreendente, seja pela disposição no esclarecimento de dúvidas ou pela troca de material entre os membros. $\mathrm{Na}$ mesma direção encontram-se os ambientes nos quais os usuários têm espaço para expor sua criação individual através de expressões literárias, musicais. É possível dizer, inclusive, que, no campo literário, os autores já consagrados se servem do ambiente em rede para se fazerem conhecer, a fim de ampliar o seu público leitor. Nestas condições, a socialização de ideias tem sido um exercício significativo, conforme anunciado por Pierre Lévy (1999).

O ambiente escolar do ensino presencial, por sua vez, também tem agregado estas formas de interação pela criação de blogs, jornais, zines, a fim de articular conteúdos curriculares. Nesta direção encontram-se inúmeros artigos de autoria de professores, que explanam a eficácia dos meios de comunicação e informação para a criação de um espaço de saber criativo e autônomo. Caso disso, é o relato de um professor de literatura brasileira que convocou a sua turma a criar blogs, a fim de estudar um determinado gênero literário, através da prática de seminários (SILVA, 2010). Uma das dificuldades encontradas nesta prática educacional presencial é o extensivo período histórico abarcado pela disciplina, que, muitas vezes, estuda um determinado gênero literário ao longo dos séculos. O professor, contudo, notou que os seus alunos não só estudaram e aprofundaram o conteúdo que Ihes havia sido designado, como também conseguiram contribuir para o estudo dos demais colegas, relacionando, trocando e discutindo saberes. Naturalmente que estas trocas foram estimuladas pelo professor, que os orientou quanto à necessidade de avaliar o intercâmbio de ideias a partir de um 
sistemático acompanhamento dos comentários no espaço dos blogs. Outra questão relevante é que a criação de blogs em torno dos estudos literários permitiu que os alunos escrevessem para além do ambiente de sala de aula, o que fez com que eles adotassem uma linguagem acessível, a fim de se aproximar de outros possíveis leitores. Uma das conclusões da experiência, segundo relato do docente, foi perceber que os alunos estavam afinados com a proposta, já que perceberam que o exercício se aplicava ao cotidiano e não era apenas uma tarefa acadêmica a ser cumprida. No entanto, ainda existem obstáculos a serem superados no que diz respeito ao acesso na rede. A referida turma de estudos literários faz parte de um grupo de estudantes universitários, mas uma das dificuldades encontradas pelo professor foi a de que nem todos os alunos tinham internet no ambiente familiar. Este foi um entrave para os trabalhos e que foi resolvido, neste caso, pelo interesse e disposição de seus alunos.

Sabe-se que as mudanças em torno das práticas sociais, que ocorrem em meio ao ambiente em rede, ainda são uma novidade para a ampla parcela da população. É necessário, nestas condições, um debate mais amplo em torno de políticas públicas, no contexto brasileiro, para que haja uma democratização no acesso à rede, pois este fator não se efetivou plenamente. Outra questão é a má qualidade técnica da internet que dificulta a operacionalização do seu uso. $\mathrm{Na}$ mesma direção, encontram-se os estímulos legais que permitirão que a ampla população tenha acesso à TV digital, que irá dinamizar recursos interativos a favor destas mudanças. $O$ acesso às tecnologias de informação e comunicação poderá inclusive fortalecer os laços entre gerações, uma vez que, hoje, se nota uma disparidade entre os que vivenciam estas ferramentas desde o início do processo da aprendizagem, os "nativos digitais", e os que não contaram com a referida estrutura.

\section{Considerações finais}

uso das tecnologias de comunicação e informação, sobretudo a internet, permite um espaço favorável para a democratização do saber e o seu livre fluxo. 
conhecimento não se restringe mais a um grupo, mas é compartilhado por um amplo número de indivíduos, independente do local em que é produzido. As distâncias, por sua vez, minimizadas pelo ambiente em rede, promovem trocas colaborativas, criativas e autônomas. A escola e a família, principais referentes de conhecimento, não podem voltar as costas às inevitáveis mudanças em sociedade, mas defender e fortalecer os valores humanos e éticos, indispensáveis a um convívio social mais harmônico. Desta maneira, o abismo que separa a geração dos letrados no ambiente digital da dos não letrados deve ser paulatinamente resolvida e, em paralelo, o último grupo pode contribuir através do diálogo, do comprometimento e do afeto, condições tão necessárias à sociedade.

Nesta perspectiva, é preciso considerar a influência da indústria cultural na formação dos brasileiros, sobretudo a mídia televisiva, que condiciona comportamentos há muitas décadas. A partir daí não basta apenas o acesso às tecnologias, mas é preciso preparar os indivíduos, tanto na qualidade da sua formação cultural, sobretudo no domínio do código escrito, quanto no exercício de uma postura ética e responsável em relação aos ambientes em rede. Enfim, as bases para uma democratização do ensino, seja presencial ou a distância, ainda estão em vias de se estruturar, pois são inúmeros os fatores que envolvem a aprendizagem nos dias atuais.

\section{THE (RE)INTERPRETATION OF POSTURES TOWARDS DISTANCE EDUCATION}

ABSTRACT: The new Information and Communication Technologies promote many changes in the social and cultural behavior nowadays. What is known is that the impact of this phenomenon reflects in many social sectors, but it is in the form of communication and education that these factors are gaining strength. In fact, the way the individual of the XXI Century makes use of and expresses himself through these instruments may define an undeniable shift in paradigm. If previous generations were accustomed to watching television programs almost always related to the applicability and selling of a product or to the determination of behavior, now, the interaction through the internet and social networking redefines postures. This article reflects the constraints imposed on the viewer through a tale of Frei Betto, so, second, discusses how the new tools of ICTs can contribute to a dynamic network learning. In this perspective, we tried to make a bibliographical survey of scientific papers dealing with the subject in question and to understand the extent to which students have made use of the resources available for networking and interaction in online learning environment. What occurs, however, is that learners can not yet empower themselves with the spaces of interaction that are at their disposal, such as forums, chats, emails, indicating that this is an obstacle to bind to the course. The misuse of language and 
lack of a sense of belonging, unfortunately, have contributed for the students to still feel reluctant or lost in the distance education environment.

KEYWORDS: Distance education. Media. Brazilian literature.

\section{Referências}

AMORETTI, M. S. Ferramentas cognitivas e interação verbal na EAD: Uma estratégia semiótica de gestão e docência. Disponível em $<$ http://www6.ufrgs.br/cursopgdr/download/UAB SuzanaAmoretti.pdf>.

ALMEIDA, Luiz Henrique Touguinha de. Aprendizagens e tecnologias contemporâneas: um novo modo de ser e de aprender? In: Revista Caminhos em Linguística Aplicada. vol.3, n. 2. Taubaté, 2010.

AXT, Margarete. Do pressuposto dialógico na pesquisa: o lugar da multiplicidade na formação (docente) em rede. Porto Alegre. In: Revista Informática na Educação: teoria e prática. v.11, n. 1, 2008.

BELLONI, M. L.. Educação à distância. São Paulo: Editora Autores Associados, 1999.

BETTO, Frei. Treze contos diabólicos (e um angélico). São Paulo: Planeta, 2005.

BOSI, Alfredo. Poesia resistência. In: O ser e o tempo da poesia. $6^{\underline{a}}$ ed. São Paulo: Companhia das Letras, 2000.

CARDOSO, Ana M. Sonho e transgressão em Caio Fernando Abreu: o entrelugar de cartas e contos. Tese de Doutorado. UFRGS, 2007.

CALVINO, Italo. Seis propostas para o novo milênio. São Paulo: Companhia das Letras, 1998.

CASTELL, Manuel. A era da informação: economia, sociedade e cultura. vol. 2. São Paulo: Paz e Terra, 2010.

LÉVY, Pierre. Cibercultura. São Paulo: Ed. 34, 1999.

. O que é virtual? São Paulo: Ed 34,1996

MARTINS, Cátia Alves \& GIRAFFA, Lúcia M. Martins. Formação do docente imigrante digital para atuar com nativos digitais no ensino fundamental. In: VIII Congresso Nacional de Educação da PUCPR (EDUCERE). Curitiba, 2008. 
MININNI, Giuseppe. Psicologia cultural da mídia. São Paulo: Girafa e Ed SESC, 2008.

MINISTÉRIO DA EDUCAÇÃO. SECRETARIA DA EDUCAÇÃO A DISTÂNCIA. Referênciais de qualidade para educação superior à distância. Brasília, 2007. Disponível em: $<$ http://portal.mec.gov.br/seed/arquivos/pdf/legislacao/refead1.pdfs.

MONTEIRO, Elis. Nativos digitais já estão dominando o mundo e transformando a forma como o ser humano se comunica. In: O Globo - Revista Digital. 2009. Disponível em: <http://oglobo.globo.com/tecnologia>. Acesso em: 12 ago. 2012.

MORAES, Heloisa J. P. Inteligência coletiva: o ciberespaço como retrato da sociedade... In: Revista Famecos, v. 18, n. 2. Porto Alegre: 2011, p. 542-556.

PASSOS, Paula Caroline Schifino Jardim; BEHAR, Patricia Alejandra. Interação e Interatividade através das interfaces de materiais educacionais digitais. In: Revista Renote, v. 9, n. 1. 2011.

SANTOS, Daniela Gehlen dos; GOMES, Andréia. Considerações acerca do Internetês. In: Revista Ensino \& Pesquisa, vol. 1, n. 5. União da Vitória: 2008.

SERRA, Daniela Tereza Santos. Afetividade, aprendizagem e educação online. Dissertação de Mestrado. Belo Horizonte: PUCMINAS, 2005.

SILVA, Marciano Lopes e. O uso de blogs e chats no ensino de literatura. In: Revista Letras de Hoje, v. 45, n. 2, Porto Alegre: 2010. p. 71-77.

VELOSO, Renato. Tecnologias da informação e comunicação: desafios e perspectivas. Saraiva: São Paulo, 2012.

Texto recebido em 05/11/2012. 